\title{
EFEITO DA DENSIDADE DE POPULAÇÃO NOS TEORES DE ÁCIDO ASCÓRBICO E CARBOIDRATOS SOLÚVEIS DE COUVE-FLOR (Brassica oleracea var. botrytis) *
}

\author{
LUIz EdUaRdo GutierRez ** \\ KeIgo Minami *** \\ MASSAR KATAYAMA \\ ILENE R. DA SILVA ***** \\ WILSON P. CÉSAR JR. *****
}

RESUMO

Os teores de carboidratos solúveis, glucose, frutose, sacarose e ácido ascórbico foram determinados em amostras de couve-flor (Bnassica oleracea var. botrytis), obtidas de tratamentos apresentando diversas densidades de plantas. O efeito do espaçamento não foi significativo para os dviersos constituintes analisados, embora o tratamento com 20.833 plantas/ha apresentasse maior teor de ácido ascórbico. O peso seco das amostras variou de 8,24 a $10,13 \%$ e ácido ascórbico de 93,1 a $113,5 \mathrm{mg} / 100 \mathrm{~g}$ de peso fresco. Os teores de carboidratos solúveis, expressos em $\mathrm{g} / 100 \mathrm{~g}$ de peso fresco foram: totais $(3,17-4,54)$ sacarose $(0,26-0,66)$, glucose $(0,92-1,50)$ e frutose $(0,91-145)$.

\section{INTRODUÇÃO}

As hortaliças desempenham na alimentação humana papel importante, sendo suplemento de nutrientes que são deficientes em outros alimentos. São importantes na neutralização de substâncias ácidas produzidas na digestão de carne e queijo, atuam como material de enchimento evitando a constipação e são considerados como fontes excelentes de sais minerais e vitaminas (THOMPSON \& KELLY, 1957).

Segundo dados citados por FILGUEIRA (1972), o consumo médio anual de hortaliças, per capita, no Brasil não atinge $10 \mathrm{~kg}$, enquanto que argentinos consomem $50 \mathrm{~kg}$, americanos $100 \mathrm{~kg}$ e italianos $140 \mathrm{~kg}$.

\footnotetext{
* Entregue para publicação em: 24/9/1976

* Departamento de Química, E.S.A. "Luiz de Queiroz"

* * Departamento de Agricultura e Horticultura, ESALQ

** Estagiário junto do Depto. Agric. e Hort., ESALQ

**** Estagiários junto ao Depto. de Química, ESALQ.
} 
Poucas referências sobre carboidratos e ácido ascórbico foram encontradas em nosso meio. FONSECA et al (1969) relataram os teores de vitamina $\mathrm{C}$ em algumas hortaliças, citando que a couve-flor apresentou $72 \mathrm{mg} / 100 \mathrm{~g}$. Os mesmos autores comentaram que não encontraram em tabelas nacionais referências a esta hortaliça.

MORTENSEN \& BULLARD (1971) citaram tabela de composição de hortaliças cultivadas na Califórnia (USA) citando que o teor de açúcares foi de 2,3\% para a variedade "bola de neve". Os principais componentes da fração carboidratos de couve-flor foram glucose e frutose com traços de sacarose (WALI \& HASSAN, 1965).

PIROVSKI \& DYANKOVA (1975) verificaram que doses elevadas de fertilizantes aumentaram o teor de ácido ascórbico de couve-flor e reduziram a matéria seca, celulose, carboidratos e cinzas. O teor de carboidratos totais de couve-flor foi reduzido quando as plantas foram pulverizadas com ácido giberélico, redução essa inversamente proporcional à quantidade de ácido aplicada (HASSIB, 1972).

No presente trabalho foi estudado o efeito da densidade de plantas sobre a composição de couve-flor em ácido ascórbico e carboidratos solúveis. Assim como apresentar dados sobre esta hortaliça, pois o conhecimento do tipo de açúcar presente é importante para nutrição. BROOK \& NOEL (1969) verificaram que frutose pode levar a aumento na deposição de gorcura corporal.

\section{MATERIAL E MÉTODOS}

Amostras de couve-flor (Brassica oleracea var. botrytis) foram obtidas de tratamentos com diversas densidades de plantas:

$\begin{array}{ll}\text { Tratamento A: } & 20.833 \text { plantas/ha } \\ \text { Tratamento B: } & 25.641 \\ \text { Tratamento C: } & 37.037\end{array}$

A variedade usada foi a Terezópolis.

Foram coletadas no período da manhã e em boas condições vegetativas. O experimento foi conduzido em terreno pertencente ao Departamento de Agricultura e Horticultura, em latossolo, tendo recebido a seguinte adubação: $20 \mathrm{~g} /$ cova de adubo 4-14-8 e $5 \mathrm{~g}$ de $\mathrm{N} /$ cova em cobertura aos 20,40 e 60 dias após o transplante. Foi feita ainda uma aplicação de borax em pulverização.

Imediatamente após a colheita, o material foi picado e separado em três porções para as análises de peso seco, ácido ascórbico e carboidratos solúveis. 
$\mathrm{O}$ peso seco foi obtido por secagem das amostras a $100-105^{\circ} \mathrm{C}$ até peso constante.

O método do 2,6 diclorofenol-indofenol descrito por JACOBS (1958) foi utilizado para análise de ácido ascórbico.

Carboidratos solúveis foram extraídos das amostras com água aquecida, em banho-maria por 30 minutos, depois de homogeinização em VIRTZ por 3 minutos. A determinação foi realizada seguindo-se o método do fenol-sulfúrico descrito por DUBOIS et alii (1956).

A separação e identificação de açúcares foi realizada segundo a técnica cromatográfica de ARZOLLA \& FONSECA (1965) e a quantificação dos açúcares segundo DUBOIS et alii (1956).

O delineamento experimental foi blocos ao acaso com 4 repetições. (PIMENTEL GOMES, 1970) e adotado o nível de 5\% de significância para comparação das médias pelos testes $F$ e Tukey.

\section{RESULTADOS E DISCUSSÃO}

No QUADRO 1 são apresentados os teores de peso seco das amostras e observa-se que não foram detectadas diferenças significativas entre os tratamentos.

Os teores de ácido ascórbico apresentados no QUADRO 2 foram superiores aos obtidos por FONSECA et alii (1969), MORTENSEN \& BULLARD (1971) e THOMPSON \& KELLY (1957). Entretanto, as análises do presente trabalho foram efetuadas imediatamente após a colheita, enquanto que FONSECA et alii (1969) analisaram amostras obtidas no mercado local, sem estabelecer tempo de colheita. Pesquisa efetuada por McMILLAN \& TODHUNTER (1946) confirmam essa observação, pois verificaram para repolho, uma perda de 5,8\% de ácido ascórbico depois de 120 minutos da colheita.

É interessante comparar os teores de ácido ascórbico de couve-flor crua e cozida pois a perda é considerável durante aquecimento. FILGUEIRA (1972) relatou perdas de $50 \%$ da couve crua para cozida.

Os teores de carboidratos solúveis totais apresentados no QUADRO 3 foram superiores aos citados por MARTENSEN \& BULLARD (1971) e THOMPSON \& KELLY (1957), diferenças essas devidas entre outras, provavelmente, a efeitos climáticos e métodos de extração.

Os resultados dos QUADROS 4 a 6 mostram os teores de açúcares simples em couve-flor e estão em desacordo com dados citados por SHALLENBERGER (1970) apenas em relação aos teores de sacarose 
que foram duas vezes maiores aos relacionados no QUADRO 4. Além disso, esse autor relatou a presença de rafinose e estaquiose.

A fração carboidratos solúveis de couve-flor apresentou como principais constituintes, sacarose, glucose e frutose perfazendo acima de $70 \%$ do total. No QUADRO 7 pode-se verificar que a proporção de sacarose, glucose e frutose na couve-flor obedeceram aproximadamente a relação 0,5:1:1. Esta mesma proporção de glucose e frutose foi observado qualitativamente por WALI \& HASSAN (1965) que encontraram apenas traços de sacarose.

As diferenças entre os teores de componentes citados no presente trabalho e na literatura poderiam ser explicadas pelo nível de adubação, pois PIROVSKI \& DYANKOVA (1975) verificaram que altas doses de fertilizantes provocaram reduções nos teores de carboidratos e aumento na quantidade de ácido ascórbico.

No QUADRO 7 pode-se observar que embora não fossem detectadas diferenças significativas entre os teores de carboidratos solúveis dos tratamentos, foi constatado que à medida que se aumentava a densidade das plantas houve diminuição na percentagem dos açúcares livres. Fato esse que poderia ser explicado pela formação de outro tipo de carboidrato não determinado neste trabalho, como por exemplo, amido.

QUADRO 1 - Matéria seca de amostras de couve-flor obtidas de diversas densidades de plantas.

Tratamentos (plantas/ha)

Repetições
A. (20833)
B (25641)
C (37037)

\begin{tabular}{rrrr}
\hline 1 & 9,18 & 10,13 & 8,60 \\
2 & 9,30 & 8,25 & 8,49 \\
3 & 9,04 & 8,24 & 9,78 \\
4 & 8,36 & 8,52 & 9,15 \\
\hline \multirow{2}{*}{ Médias } & 8,97 & 8,79 & 9,01 \\
\hline
\end{tabular}

C.V. $=8,21 \% \quad$ F não significativo 
QUADRO 2 - Teores de ácido ascórbico de amostras de couve-flor obtidas de diversas densidades de plantas (Expresso em $\mathrm{mg} / 100 \mathrm{~g}$ peso fresco).

\begin{tabular}{cccc}
\hline \multirow{2}{*}{ Repetições } & \multicolumn{3}{c}{ Tratamentos (plantas'/ha) } \\
\cline { 2 - 4 } & A (20833) & B (25641) & C (37037) \\
\hline \hline 1 & 106,1 & 104,0 & 89,0 \\
3 & 100,4 & 101,4 & 98,0 \\
4 & 103,2 & 94,6 & 94,1 \\
Médias & 113,6 & 93,1 & 98,8 \\
\hline
\end{tabular}

$\mathrm{C} . \mathrm{V} .=5,92 \% \quad \mathrm{~F}$ não significativo

QUADRO 3 - Teores de carboidratos solúveis totais de amostras de couve-flor obtidas de diversas densidades de plantas (Expresso em $\mathrm{g} / 100 \mathrm{~g}$ peso fresco).

\begin{tabular}{cccc}
\hline \multirow{2}{*}{ Repetições } & \multicolumn{3}{c}{ Tratamentos (plantas/ha) } \\
\cline { 2 - 4 } & A (20833) & B (25641) & C (37037) \\
\hline 1 & 3,08 & 3,37 & 3,50 \\
2 & 3,93 & 4,50 & 3,75 \\
3 & 3,85 & 3,96 & 4,54 \\
4 & 3,65 & 3,56 & 3,17 \\
\hline Médias & 3,63 & 3,93 & 3,74 \\
\hline
\end{tabular}

C.V. $=9,25 \% \quad$ F não significativo

QUADRO 4 - Teores de sacarose de amostras de couve-flor obtidas de diversas densidades de plantas (Expresso em $\mathrm{mg} / 100 \mathrm{~g}$ peso fresco).

\begin{tabular}{|c|c|c|c|}
\hline \multirow{2}{*}{ Repetições } & \multicolumn{3}{|c|}{ Tratamentos (plantas/ha) } \\
\hline & A $(20833)$ & B $(25641)$ & $C(37037)$ \\
\hline 1 & 0,62 & 0,33 & 0,61 \\
\hline 2 & 0,30 & 0,66 & 0,41 \\
\hline 3 & 0,30 & 0,26 & 0,35 \\
\hline 4 & 0,59 & 0,50 & 0,28 \\
\hline Médias & 0,45 & 0,44 & 0,41 \\
\hline
\end{tabular}

C.V. $=39,48 \% \quad$ F não significativo 
QUADRO 5 - Teores de glucose de amostras de couve-flor obtidas de diversas densidades de plantas (Expresso em $\mathrm{mg} / 100 \mathrm{~g}$ peso fresco).

\begin{tabular}{cccc}
\hline \multirow{2}{*}{ Repetições } & \multicolumn{3}{c}{ Tratamentos (plantas/ha) } \\
\cline { 2 - 4 } & $\mathrm{A}(20833)$ & $\mathrm{B}(25641)$ & $\mathrm{C}(37037)$ \\
\hline \hline 1 & 1,31 & 1,04 & 1,26 \\
2 & 1,50 & 1,30 & 1,01 \\
3 & 1,21 & 1,41 & 1,07 \\
4 & 1,04 & 0,92 & 1,13 \\
\hline Médias & 1,26 & 1,17 & 1,12 \\
\hline
\end{tabular}

$\mathrm{C} . \mathrm{V} .=15,35 \% \quad$ F não significativo

QUADRO 6 - Teores de frutose de amostras de couve-flor obtidas de diversas densidades de plantas (Expresso em $\mathrm{mg} / 100 \mathrm{~g}$ peso fresco).

\begin{tabular}{cccc}
\hline \multirow{2}{*}{ Repetições } & \multicolumn{3}{c}{ Tratamentos (plantas/ha) } \\
\cline { 2 - 4 } & A $(20833)$ & B (25641) & C (37037) \\
\hline 1 & 1,18 & 1,21 & 1,16 \\
2 & 0,91 & 1,33 & 1,19 \\
3 & 1,06 & 1,42 & 1,28 \\
4 & 1,29 & 1,45 & 1,20 \\
\hline Médias & 1,11 & 1,35 & 1,21 \\
\hline C.V. $=8,92 \%$ & F não significativo &
\end{tabular}

QUADRO 7 - Carboidratos solúveis de couve-flor (Expresso em $\mathrm{g} / 100 \mathrm{~g}$ peso fresco).

\begin{tabular}{lccc}
\hline \multirow{2}{*}{ Repetições } & \multicolumn{3}{c}{ Tratamentos (plantas/ha) } \\
\cline { 2 - 4 } & $\mathrm{A}(20833)$ & $\mathrm{B}(25641)$ & $\mathrm{C}(37037)$ \\
\hline \hline Solúveis Totais & 3,63 & 3,93 & 3,74 \\
Sacarose & 0,45 & 0,44 & 0,41 \\
Glucose & 1,26 & 1,17 & 1,21 \\
Frutose & 1,11 & 1,35 & 1,21 \\
Açúcares simples & & & \\
\hline \multicolumn{1}{c}{ totais } & 77,7 & 74,8 & 73,3 \\
\hline
\end{tabular}




\title{
CONCLUSÃO
}

\section{Pelos resultados obtidos pode-se concluir que não houve efeito significativo do espaçamento utilizado sobre os teores de carboidratos solúveis e ácido ascórbico.}

\section{SUMMARY}

\author{
EFFECT OF PLANT DENSITY ON SOLUBLE CARBOHYDRATES AND \\ ASCORBIC ACID CONTENTS OF CAULIFLOWER (BRASSICA OLERACEA \\ CV. BOTRYTIS) *
}

Total soluble carbohydrates, glucose, fructose, sucrose and ascorbic acid contents were determined in cauliflower (Brassica oleracea CV. botrytis) samples. The effect of plants densities was studied in this paper. Statistically differences were not observed amoung treatments, although the samples from 20833 plants/ha showed higher level of ascorbic acid. Dry weight varied from 8.24 to $10.13 \%$ and ascorbic acid contents varied from 93.1 to $113.5 \mathrm{mg} / 100 \mathrm{~g}$ fresh weight basis. Soluble carbohydrates, in $\mathrm{g} / 100 \mathrm{~g}$ fresh weight basis, were: total (3.17-4.54), sucrose $(0.26-0.66)$, glucose $(0.92-1.50)$ and fructose $(0.91-1.45)$.

\section{LITERATURA CITADA}

ARZOLlA, J.D.P. \& H. FONSECA. 1965. Cromatografia de Açúcares. Boletim Didático 11. ${ }^{\circ}$ 7. E.S.A. "Luiz de Queiroz". 19 pp.

BROOK, M. and P. NOEL. 1969. Influence of dietary liquid glucose, sucrose and fructose on body fat formation. Nature, 222: 562-563.

DUBOIS, M., K.A. GILLES, J.K. HAMILTON, P.A. REBERS and F. SMITH. 1956. Colorimetric method for determinations of sugars and related substances. Anal. Chem., $28: 350-356$.

FILGUEIRA, R.A.R. 1972. Manual de Olericultura. Editora Ceres. São Paulo. 451 p.

FONSECA, H., J.N. NOGUEIRA e A.M.S. MARCONDES. 1969. Teor de ácido ascórbico e beta-caroteno em frutas e hortaliças brasileiras. Archivos Latinoamericanos de Nutricion, $19: 9-16$.

HASSIB, M. 1972. Effect of gibberellic acid application upon growth, carbohydrate and nitrogen assimilation by cauliflower. Gartenbauwissenschaft, 37: 305-309. In: Horticultural Abstracts, $43: 749$.

JACOBS, M.B. 1958. The Chemical Analysis of Foods and Foods Products. Van Nostrand. New York. 971 p.

McMILlAN, T.J. and E.N. TODHUNTER. 1946. Dehydroascorbic acid in cabrage. Science, 103 : 196-197. 
MORTENSEN, E. \& E. BULLARD. 1971. Horticultura Tropical y Subtropical. $2 .^{\mathrm{a}}$ ed. Editora Galve. México. 182 p.

PIMENTEL GOMES, F. 1970. Curso de Estatística Experimental. 4. ${ }^{a}$ ed. Livraria Nobel. São Paulo. 430 p.

PIROVSK|, M. and D. DYANKOVA. 1975. The effect of mineral fertilization on the vegetative development, yield and quality of cauliflower. Gradinarska i Losarska Nauka, 12: 80-85. In: Horticultural Abstracts, 46: 106.

SHALLENBERGER, R.S. 1970. Nutritional quality in fruits and vegetables. HortScience, 5: $100-101$.

THOMPSON, H.C. and W.C. KELLY. 1957. Vegetable crops. 5th ed. Mc Grau Hill. New York. 611 p.

WALI, Y.A. and Y.M. HASSAN. Qualitative chromatographic survey of the sugars prevailing in some horticultural crops. Proc. Amer. Soc. Hort. Sci., 87: 264-269. 